06

\title{
Особенности описания импульсной электрической прочности полимерных диэлектриков
}

\author{
(ㄱ Ю.Э. Адамьян, С.И. Кривошеев, С.Г. Магазинов
}

Санкт-Петербургский политехнический университет Петра Великого, Санкт-Петербург, Россия

E-mail: wiradam@rambler.ru

Поступило в Редакцию 19 ноября 2020г.

В окончательной редакции 19 ноября 2020г.

Принято к публикации 27 ноября 2020 г.

\begin{abstract}
Предложен сценарий использования модели полевой ионизации макромолекул для описания импульсного пробоя полимерных диэлектриков, учитывающий определяющее влияние пространственно-полевой неоднородности реального диэлектрика в формировании „очагов“ ионизации и перераспределении носителей заряда. Приведено обоснование выбора определяющих параметров модели: ширины энергетической щели и частотного фактора. Показана возможность использования этих параметров для описания импульсной прочности полимеров как в однородном, так и в резко неоднородном электрическом поле (на примере полиметилметакрилата).
\end{abstract}

Ключевые слова: полевая ионизация, вольт-секундная характеристика, импульсная прочность диэлектрика, носитель заряда.

DOI: 10.21883/PJTF.2021.05.50679.18621

Несмотря на очевидную актуальность проблемы моделирования импульсного пробоя полимерных диэлектриков, построение физической модели, удовлетворительно описывающей экспериментальные данные, до сих пор является нерешенной задачей. Во многих случаях связь между напряженностью поля и временем разрушения носит довольно сложный характер $[1,2]$ и подвержена значительному статистическому разбросу. На данный момент не существует единой точки зрения на механизм пробоя полимерных диэлектриков. Одним из распространенных представлений о механизме пробоя при временах $1 \mathrm{~ns}-1 \mu \mathrm{s}$ является лавинный пробой, основанный на механизме ударной ионизации $[3,4]$. Однако такой подход встречает значительные трудности при описании пробоя тонких пленок [5]. Для оценки времени развития импульсного пробоя полимера можно использовать модель, предложенную в работе [6]. В этой модели механизм пробоя связывается с полевой ионизацией макромолекул при туннельном переходе электрона с уровня высшей занятой молекулярной орбитали макромолекулы на низшую свободную орбиталь другой молекулы. Взрывообразное возрастание концентрации носителей зарядов происходит при достижении критического значения концентрации дырок $p_{c r}=2 \cdot 10^{17} \mathrm{~cm}^{-3}$ вследствие самоускорения процесса полевой ионизации молекул за счет дебаевского экранирования. Константа скорости туннельной ионизации $k_{\mathrm{HL}}(p)$ определяется в соответствии с формулой

$$
k_{\mathrm{HL}}(p)=v_{0} D_{\mathrm{HL}}
$$

Здесь $D_{\mathrm{HL}}=\exp \left(-\frac{4 \sqrt{2 m}}{3 e \hbar} \frac{\Delta^{3 / 2}}{E}\right)-$ прозрачность потенциального барьера, $v_{0} \approx 10^{16} \mathrm{~s}^{-1}$ - частотный фактор, $E$ - напряженность поля, $m$ - масса электрона, $\hbar$ - постоянная Планка, $\Delta$ - высота потенциального барьера, рассчитанная с учетом ее снижения за счет дебаевского экранирования: $\Delta=E_{g}-\Delta I(p)$, где $E_{g}-$ ширина энергетической щели.

Проведенное в [7] сопоставление экспериментальных данных и результатов расчета по модели полевой ионизации показало, что зависимость напряженности пробоя от скорости нарастания импульса напряжения в эксперименте выражена значительно сильнее, а расчетная пробивная напряженность при малой скорости нарастания сильно завышена. При этом наблюдаемые несоответствия связываются авторами с влиянием объемного заряда, накапливающегося в диэлектрике при воздействии импульса напряжения.

Очевидно, что адекватность модели определяется соответствием результатов моделирования экспериментальным данным. В модели полевой ионизации основными параметрами, влияющими на поведение расчетной вольт-секундной характеристики (BCX), являются ширина энергетической щели $E_{g}$ и частотный фактор $v_{0}$ [6].

Цель настоящей работы - ревизия физического смысла и значений используемых авторами основных параметров для улучшения согласования результатов расчетов и экспериментов.

Согласно [8], пороговой напряженностью электрического поля, при котором начинается существенный рост тока при приложении постоянного электрического поля к пленке полиэтилентерефталата (РЕT), является величина $E_{i}=(0.7-0.8) \cdot 10^{8} \mathrm{~V} / \mathrm{m}$. Такая величина напряженности начала образования дырок получается при использовании в реализованной нами модели полевой ионизации величины $E_{g}=3.8 \mathrm{eV}$ (в [7] при моделировании использовалось значение $\left.E_{g}=6-7 \mathrm{eV}\right)$. 
Пробные расчеты с использованием приведенного выше значения показали, что удовлетворительное согласие с экспериментами достигается при уменьшении частотного фактора на несколько порядков по сравнению с величиной, используемой авторами [7]. Представляется возможным выдвинуть гипотезу, обосновывающую столь значительное отклонение от параметров исходной модели. Если сделать предположение о дефектах структуры полимера как об основном факторе, определяющем момент начала ионизации, величина $E_{g}$ должна быть снижена по сравнению с теоретическими значениями. Возникший на какой-либо неоднородности „очаг“" ионизации приведет к резкому локальному росту концентрации свободных носителей заряда вследствие механизма положительной обратной связи, в основе которого лежит снижение высоты потенциального барьера за счет дебаевского экранирования зарядов. Для выравнивания концентрации носителей по объему диэлектрика необходимо время, которое определяется характерной длиной $\lambda$ и скоростью дрейфа носителей заряда $\tau_{i} \sim \lambda / E \mu$, где $\mu-$ подвижность носителей заряда. При этом характерная длина может быть определена как величина среднего расстояния между дефектами. Как минимум, она должна составлять несколько межчастичных расстояний. Если $M_{0}$ - начальная концентрация способных ионизоваться фрагментов макромолекул - равна примерно $10^{27} \mathrm{~m}^{-3}$, то среднее расстояние между ними $d=M_{0}^{-3}$, т. е. около $10^{-9} \mathrm{~m}$. При величине подвижности зарядов $\mu=10^{-8} \mathrm{~m}^{2} /(\mathrm{V} \cdot \mathrm{s})$ [7] получаем для напряженности, близкой к пробивной, значение частотного фактора $v_{0}=1 / \tau_{i}$ порядка $10^{9} \mathrm{~s}^{-1}$. В такой трактовке физический смысл частотного параметра меняется; по сути, он определяет усредненную на пространственном масштабе неоднородности скорость ионизации среды за счет дрейфа носителей заряда из центра ионизации. Учитывая возможное снижение подвижности носителей заряда с ростом энерговклада в среду, в первом приближении можно считать скорость дрейфа частиц $v_{d r}=E \mu$ и соответственно частотный фактор не зависящими от напряженности поля.

На рис. 1 (кривая 1) представлены расчетные и экспериментальные точки ВСХ согласно данным [7] по пробою РЕТ толщиной $3 \mu \mathrm{m}$ в поле, близком к однородному, при значении $v_{0}=4.2 \cdot 10^{9} \mathrm{~s}^{-1}$ и $E_{g}=3.8 \mathrm{eV}$. Далее был проведен подбор параметров модели для описания данных работы [9] по пробою полиметилметакрилата (РММА) толщиной $0.15 \mathrm{~mm}$ в однородном поле. На рис. 1 (кривая 2) показаны результаты сопоставления экспериментов и расчетов при $v_{0}=9 \cdot 10^{7} \mathrm{~s}^{-1}$ и $E_{g}=2.25 \mathrm{eV}$.

Для проверки степени универсальности подобранных параметров в дальнейших расчетах была выбрана более сложная геометрия поля в системе острие-плоскость при пробое РММА импульсами, близкими к прямоугольным. В данном расчете использовались те же параметры модели, что и в однородном поле. Для расчетов в неоднородном поле применялась следующая постановка.

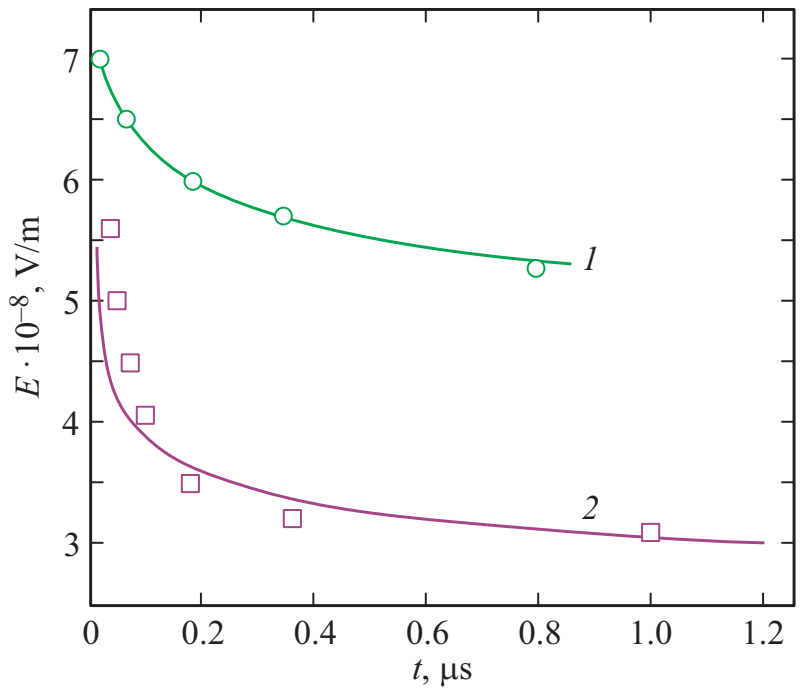

Рис. 1. Сопоставление расчетных зависимостей и экспериментальных данных из работ [7] (1) и [9] (2).

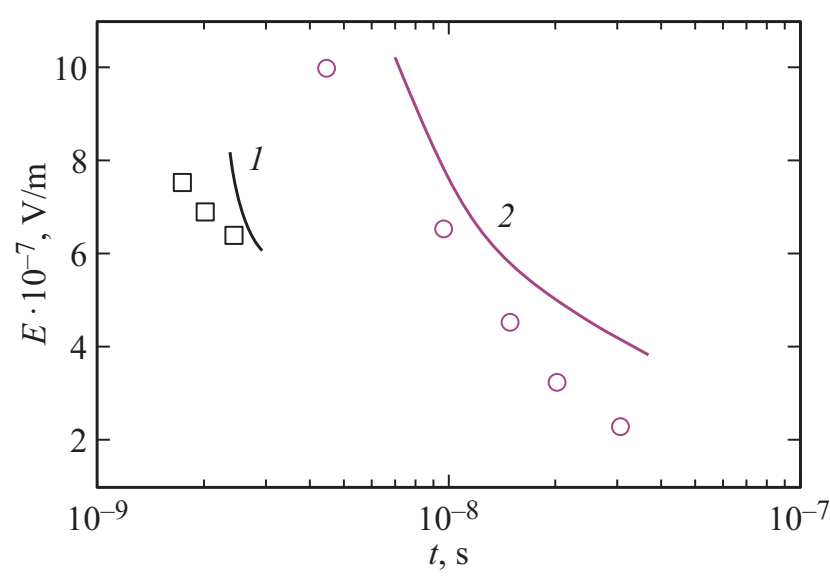

Рис. 2. Зависимость средней пробивной напряженности от времени воздействия для РММА в геометрии острие-плоскость при положительной полярности острия. 1 - по данным [10], 2 - по данным [11].

Расчетная область разбивалась на систему подобластей вдоль оси электрода. Распределение электростатического поля рассчитывалось с помощью программы COMSOL Multiphysics. При достижении в подобласти, ближайшей к электроду, критической концентрации носителей заряда подобласть исключалась из расчета как „пробитая““ и потенциал электрода переносился на границу следующей подобласти с сохранением радиуса кривизны электрода.

Как показали оценки, влияние объемного заряда, накопленного за счет ионизации в „непробитых“ подобластях, на распределение поля является незначительным. Данные по ВСХ пробоя РММА толщиной $400 \mu \mathrm{m}$ прямоугольным импульсом положительной полярности, подаваемым на острие с радиусом закругления $1 \mu \mathrm{m}$, для минимального времени пробоя взяты из работы [10]. 
Данные для пробоя РММА толщиной $3 \mathrm{~mm}$ прямоугольным импульсом положительной полярности с радиусом закругления острия $60 \mu \mathrm{m}$ для среднего времени пробоя взяты из работы [11] (рис. 2). Как видно из рисунка, расчет дает правильный порядок величины времени пробоя, что может считаться удовлетворительным с учетом реального разброса экспериментальных данных.

В экспериментах при отрицательной полярности острия время задержки пробоя почти на порядок больше, чем при положительной полярности, даже при более высокой средней напряженности [11]. Удовлетворительное совпадение расчета с экспериментом в режиме положительного острия соответствует условию движения дырок от острия в область более слабого поля. В противном случае (отрицательное острие) сделанное предположение о выравнивании концентрации носителей заряда за счет дрейфа в электрическом поле не может реализоваться.

Отличие параметров модели в предложенном подходе от модели пробоя, описанной в [7], связано с учетом наличия возможных дефектов в пространственноэнергетической структуре реального диэлектрического материала.

Используемая при расчетах ширина энергетической щели является параметром, характеризующим порог полевой ионизации в области структурных дефектов материала. Различие подобранных величин $E_{g}$ для PЕТ $(3.8 \mathrm{eV})$ и РMMA $(2.25 \mathrm{eV})$ коррелирует со значительной разницей их статической пробивной напряженности: $E_{b r}=1.60 \cdot 10^{8} \mathrm{~V} / \mathrm{m}$ для РЕТ и $0.2 \cdot 10^{8} \mathrm{~V} / \mathrm{m}$ для РММА.

Что касается величины частотного фактора $v_{0}$, определяющего усредненную на пространственном масштабе неоднородности скорость ионизации среды, то более высокое значение $v_{0}$ для пленки PET может быть связано с ее значительно более однородной структурой, чем у листового РММА, и соответственно с меньшим временем выравнивания концентрации носителей заряда.

Предложенный подход к моделированию импульсной прочности диэлектриков позволяет при известной $\mathrm{BCX}$, полученной при определенных условиях, установить параметры модели, описывающей поведение импульсной прочности полимера в других конфигурациях электрического поля.

\section{Благодарности}

Результаты работы получены с использованием вычислительных ресурсов суперкомпьютерного центра СанктПетербургского политехнического университета Петра Великого (www.scc.spbstu.ru).

\section{Финансирование работы}

Работа выполнена при поддержке программы 5-100 Санкт-Петербургского политехнического университета Петра Великого.

\section{Конфликт интересов}

Авторы заявляют, что у них нет конфликта интересов.

\section{Список литературы}

[1] D.B. Watson, J. Phys. D: Appl. Phys., 5 (2), 410 (1972). DOI: $10.1088 / 0022-3727 / 5 / 2 / 323$

[2] D.B. Watson, IEEE Trans. Electr. Insul., 8 (3), 73 (1973). DOI: 10.1109/TEI.1973.299247

[3] Г.И. Сканави, Изв. Томск. политехн. ин-та, 91, 7 (1956).

[4] L. Zhao, J.C. Su, C.L. Liu, AIP Adv., 10 (3), 035206 (2020). DOI: $10.1063 / 1.5110273$

[5] В.А. Закревский, Н.Т. Сударь, ФТТ, 47 (5), 931 (2005). [Пер. версия: 10.1134/1.1924862].

[6] В.А. Закревский, Н.Т. Сударь, ФТТ, 55 (7), 1298 (2013). [Пер. версия: 10.1134/S1063783413070354].

[7] В.А. Закревский, В.А. Пахотин, Н.Т. Сударь, ЖТФ, 89 (1), 120 (2019). DOI: 10.21883/JTF.2019.01.46972.98-18 [Пер. версия: 10.1134/S1063784219010262].

[8] K. Miyairi, M. Ieda, in Proc. of First Int. Conf. on conduction and breakdown in solid dielectrics (IEEE, 1983), p. 428-432. DOI: 10.1109/ICSD.1983.7411552

[9] А.В. Астафуров, А.А. Воробьев, Г.А. Воробьев, К.М. Кевролева, Изв. Томск. политехн. ин-та, 94, 16 (1958).

[10] I. Kitani, K. Arii, IEEE Trans. Electr. Insul., 15 (2), 134 (1980). DOI: 10.1109/TEI.1981.298353

[11] В.С. Королев, Н.М. Торбин, Изв. Томск. политехн. ин-та, 184, 121 (1970). 